Open Access

\title{
Genetic variation and relationships in the mitochondrial DNA D-loop region of Qinghai indigenous and commercial pig breeds
}

Junxia Zhang ${ }^{1,2}$, Baochun Yang ${ }^{1,2}$, Xiaocheng Wen ${ }^{1,2^{*}}$ and Guogiang Sun ${ }^{2}$

\footnotetext{
*Correspondence: 506944045@qq. com

${ }^{1}$ State Key Laboratory of Plateau Ecology and Agriculture, Qinghai University, Xining 810016, Qinghai, China

${ }^{2}$ College of Agriculture and Animal Husbandry, Qinghai University,

Xining, Qinghai, China
}

\begin{abstract}
Background: Bamei pigs are special germplasm resources in Qinghai. In the specific environment of the Qinghai plateau, local breeds, through long-term natural and artificial selection, have acquired a relatively stable population structure and genetic diversity. This study revealed Bamei pigs' genetic diversity at the molecular level and the degree of introgression of commercial breeds into Bamei pigs.

Methods: The mitochondrial DNA D-loop region was amplified and sequenced using the ABI 3130 DNA sequencer. Sequences were collected, edited and aligned using the MEGA 5.0, DNASTAR and ClustalX 1.81 software. Haplotypes of all sequences and genetic diversity were analyzed by DnaSP 5.0 software.

Results and conclusions: We identified a total of 73 polymorphic sites in our 489 novel sequences, including 1 single variable site and 72 parsimony informative sites. Genetic diversity was analyzed in this study. The results showed that haplotype diversity, nucleotide diversity and the average number of nucleotide differences of Bamei pigs were lower than those of commercial pigs. Synthetic evaluation of genetic diversity through principal component analysis indicated that Bamei pigs also showed low genetic diversity. In summary, the results of sequence analysis showed that Bamei pigs were low in genetic diversity, and the introgression of commercial pigs into Bamei pigs was serious.
\end{abstract}

Keywords: Mitochondrial DNA, Genetic variation, Bamei pig, Commercial pig

\section{Background}

With the high intensification of pig production, highly productive breeds became predominant in the pig production system, and the quantity of indigenous breeds was decreased, so breed resource protection become more important [1]. The Bamei pig is the indigenous pig breed in Qinghai Province of China, where there is a plateau continental climate. Under the influence of the ecological environment and natural and artificial selection, the Bamei pig was developed, which has the characteristics of good adaptability, high resistance, large litter size, good maternal qualities, high fat deposition ability, good meat quality and flavor, genetic stability, strong inbreeding resistance, adaptation to cold climate conditions and extensive feeding and management. However, they have some shortcomings, for

(c) The Author(s). 2018 Open Access This article is distributed under the terms of the Creative Commons Attribution 4.0 International License (http://creativecommons.org/licenses/by/4.0/), which permits unrestricted use, distribution, and reproduction in any medium, provided you give appropriate credit to the original author(s) and the source, provide a link to the Creative Commons license, and indicate if changes were made. The Creative Commons Public Domain Dedication waiver (http://creativecommons.org/ publicdomain/zero/1.0/) applies to the data made available in this article, unless otherwise stated. 
example, slow growth, low lactation quantity, and low fattening benefit [2]. In the past 50 years, Qinghai Province has introduced some pig breeds such as Berkshire, white, Landrace, Duroc, Hampshire, England, Yorkshire and other foreign breeds, which were crossed with the Bamei pig through an economic hybrid and three-way hybrid. The offspring were fed with high nutritional diets. Although the production performance was increased, the Bamei pig breed is at risk of extinction [3].

mtDNA sequence analysis has enabled important investigation of the origin and diversification of animal populations [4-8]. mtDNA contains the displacement (D)-loop, containing regulatory sequences controlling both replication and transcription of mtDNA [1,9]. In the present study, we examined sequence variation in mtDNA from Bamei pig populations and commercial pig populations. We also assessed the relative impact of commercial pigs on Bamei pig populations. This study aimed to acquire information on Bamei pig genetic diversity. The findings will be helpful for conservation and sustainable use of Bamei pig resources.

\section{Methods}

\section{Sampling and sequencing}

A total of 489 samples, including 489 individuals (4 pig breeds) distributed in Qinghai Province of China, were collected. (Information on collected samples is provided in Table 1.) Only ear tissues were collected into microcentrifuge tubes containing $75 \%$ ethanol, and preserved at $-80{ }^{\circ} \mathrm{C}$. Animals were released immediately following treatment of the wounds with antiseptic.

Genomic DNA was extracted using the phenol-chloroform extraction method [10]. A fragment of the D-loop region was amplified using the primers 5 '-CCAAAAACAAAGCA GAGTGTAC-3' and 5'-CGTTATGAGCTACCGTTATA-3'. The PCR reaction mixture consisted of $25 \mu \mathrm{L}$, containing $12.5 \mu \mathrm{L} 2 \times$ Eco Taq PCR Supermix containing $1 \mathrm{U}$ Taq polymerase, $500 \mathrm{mM}$ dNTPs, and 10×Taq buffer (Beijing TransGen Biotech Co., Ltd., China), $0.1 \mu \mathrm{g}$ of template DNA, $0.4 \mu \mathrm{L}$ of $10 \mathrm{pmol} / \mathrm{mL}$ of each primer and $11.6 \mu \mathrm{L}$ of $\mathrm{ddH}_{2} \mathrm{O}$. The cycling conditions were initial denaturation at $94{ }^{\circ} \mathrm{C}$ for $5 \mathrm{~min}$, followed by 33 cycles of $94^{\circ}$ $\mathrm{C}$ for $30 \mathrm{~s}, 56^{\circ} \mathrm{C}$ for $30 \mathrm{~s}$ and $72{ }^{\circ} \mathrm{C}$ for $30 \mathrm{~s}$, and a final extension for $5 \mathrm{~min}$ at $72{ }^{\circ} \mathrm{C}$. Amplified DNA fragments were purified following agarose gel electrophoresis and sequenced using the ABI 3130 DNA sequencer (Applied Biosystems, Foster City, CA, USA).

\section{Data analysis}

A total of 489 mtDNA D-loop sequences were obtained and analyzed in this study, including 115 sequences from indigenous pigs (Bamei pigs) and 374 sequences from commercial pigs (Duroc, Landrace and Yorkshire).

Table 1 Characteristics of samples

\begin{tabular}{lllll}
\hline Breed/population & Category & Sample size & Source & Sampling site \\
\hline Bamei pig & Indigenous & 115 & Ear tissue & Qinghai Province \\
Duroc & Commercial & 101 & Ear tissue & Qinghai Province \\
Landrace & Commercial & 108 & Ear tissue & Qinghai Province \\
Yorkshire & Commercial & 165 & Ear tissue & Qinghai Province \\
Total & & 489 & & \\
\hline
\end{tabular}


Original sequence data were obtained using the ABI PRISM DNA sequencer software. Sequences were edited using the DNASTAR software and aligned using ClustalX 1.81 [11]. In all sequences the length of alignment was reduced to $435 \mathrm{bp}$, and these were used to perform additional analyses. In addition, the haplotypes of all sequences and genetic diversity were analyzed using DnaSP 5.0 software [12]. Correlation analysis and principal component analysis (PCA) were investigated by SPSS 19.0.

\section{Results}

\section{Genetic diversity analysis}

The 435 bp control region of mtDNA was used to analyze single nucleotide polymorphisms (SNPs) for all 489 sequences. No insertion/deletions (indels) were detected in our novel sequences. We identified a total of 73 polymorphic sites, including 1 single variable site and 72 parsimony informative sites. The four types of nucleotide mutations identified were transitions, transversions, insertions and deletions. The transition: transversion ratio $\mathrm{R}$ ( Ts/Tv) was 13.29:1, indicating a strong transitional bias that is common in mammalian mitochondrial evolution [13].

The genetic diversity of Bamei pigs and commercial pigs was calculated (Table 2). Haplotype diversity $(\mathrm{Hd})$ of pig populations was between 0.491 and 0.856 . All commercial pigs had high haplotype diversities of over 0.7. Yorkshire had the highest haplotype diversity $(0.856 \pm 0.018)$. Bamei pigs had the lowest haplotype diversity $(0.491 \pm 0.055)$. The result showed that haplotype diversity of Bamei pigs was lower than that of commercial pigs. Nucleotide diversities (Pis) were in the range 0.00264-0.01559. Landrace had the highest nucleotide diversity (0.01564), while Bamei pigs had the lowest (0.00264). Average nucleotide diversity of commercial pigs was higher than that of Bamei pigs. For all varieties of pigs the average number of nucleotide differences (Ks) was between 6.815 and 1.15; for Landrace it was the highest (6.815), and for Bamei pigs the lowest (1.15) - lower than for all commercial pigs.

The correlation of $\mathrm{Pi}, \mathrm{Hd}$ and $\mathrm{K}$ was analyzed using SPSS 19.0 (Table 3). The results showed that $\mathrm{Hd}, \mathrm{Pi}$ and $\mathrm{K}$ were positively correlated with each other, which indicated that all three indexes influenced the abundant degree of genetic diversity. Principal component analysis (PCA) was used for synthetic assessment of genetic diversity. The results are shown in Table 4. We obtained a synthesized assessment score $(\mathrm{Fz})$. The $\mathrm{Fz}$ score indicated the highest genetic diversity in Landrace and the lowest for Bamei pigs.

Table 2 Parameters for determination of genetic diversity of pig populations

\begin{tabular}{llllllll}
\hline Code & Breed/Population & Size & $\mathrm{S}$ & $\mathrm{H}$ & $\mathrm{Hd} \pm \mathrm{SD}$ & $\mathrm{Pi}$ & $\mathrm{K}$ \\
\hline CHN-QH & Bamei & 115 & 10 & 10 & $0.491 \pm 0.055$ & 0.00264 & 1.15 \\
DUR & Duroc & 101 & 18 & 11 & $0.732 \pm 0.033$ & 0.00947 & 4.12 \\
LAN & Landrace & 108 & 18 & 18 & $0.853 \pm 0.02$ & 0.01567 & 6.815 \\
YOR & Yorkshire & 165 & 27 & 24 & $0.856 \pm 0.018$ & 0.01559 & 6.768 \\
\hline
\end{tabular}

S: Number of polymorphic (segregating) sites

$\mathrm{H}$ : Number of haplotype

Pi: Nucleotide diversity, Nei 1987, eqs. 10.5 or 10.6 (Masatoshi Nei)

K: Average number of nucleotide differences; Tajima 1983, eq. A3 (Tajima)

Hd \pm SD: Haplotype (gene) diversity and sampling variance, Nei 1987, eqs. 8.4 and 8.12 but replacing $2 \mathrm{n}$ with $\mathrm{n}$. The standard deviation (or standard error) is the square root of the variance (Masatoshi Nei) [13] 
Table 3 Correlation matrix between indexes

\begin{tabular}{llll}
\hline Item & Hd & Pi & K \\
\hline $\mathrm{Hd}$ & 1.000 & .990 & .990 \\
$\mathrm{Pi}$ & .990 & 1.000 & 1.000 \\
$\mathrm{~K}$ & .990 & 1.000 & 1.000 \\
\hline
\end{tabular}

\section{Haplotype analysis of sequences}

The 435 bp control region of mtDNA was used to calculate haplotypes for all 489 sequences. In total, 43 haplotypes were identified according to the distribution of variable sites (Table 5). Distribution frequencies of haplotypes indicated no equilibrium. The highest frequency haplotype was Hap34, which was shared by 97 sequences. The lowest frequency haplotypes were 26, and each haplotype harbored a sequence. Another 17 haplotypes were shared by two or more sequences. Hap31 and Hap34 were advantageous haplotypes which were present in more than 90 sequences. The Bamei porcine population shared 11 haplotypes. The commercial porcine population shared 36 haplotypes.

\section{Introgression of commercial pigs into Qinghai indigenous pigs}

Forty-three haplotypes in 489 individuals from indigenous and commercial breeds were identified. Eleven haplotypes were identified in indigenous pigs and 36 haplotypes were identified in commercial pigs. Seventeen shared haplotypes were identified and distributed in 96 indigenous and 123 commercial pigs. The ratio of the number of indigenous pigs with shared haplotypes and the total of indigenous pigs $(\mathrm{Sc} / \mathrm{S})$ showed the degree to which indigenous pigs were affected by commercial pigs. Sc/S was $83.48 \%$ (Table 6). Our data showed that Bamei breed was impacted by commercial breeds (Landrace, Yorkshire and Duroc).

\section{Discussion}

\section{Genetic diversity of Bamei and commercial porcine populations}

$\mathrm{Hd}, \mathrm{Pi}$ and $\mathrm{K}$ were the basic parameters which were used to assess genetic diversity. Hd is a measure of the uniqueness of a particular haplotype in a given population [14], which reflects haplotype abundance in a population. Pi and $\mathrm{K}$ measure the degree of intrapopulation haplotype mutation [11]. Our study examined genetic diversity of Bamei and commercial porcine populations, and the results showed that the genetic diversities of both Bamei and commercial porcine populations were low, which is consistent with the trend of the genetic diversity of global livestock populations declining [15]. Bamei pigs had the lowest haplotype diversity due to commercial hybridization. Bamei pigs have a low growth rate, so commercial pigs were used to cross with Bamei pigs to improve their performance. The Bamei population is, therefore, becoming smaller, and

Table 4 Rank and general scores of principal components of different populations

\begin{tabular}{llll}
\hline Code & Breed/population & $F_{Z}\left(F_{1}\right)$ & Rank \\
\hline CHN-QH & Bamei & -2.345 & 4 \\
DUR & Duroc & -0.132 & 3 \\
LAN & Landrace & 0.405 & 1 \\
YOR & Yorkshire & 0.001 & 2 \\
\hline
\end{tabular}


Table 5 The distribution of variable sites of mtDNA D-loop in pig populations

\begin{tabular}{|c|c|c|c|c|c|c|}
\hline $\mathrm{H}$ & \begin{tabular}{c}
\multicolumn{1}{c}{ Polymorphism sites } \\
22456771111111111111111222222222222223333333333444 \\
38322681122333445558888113344477788890001124699001 \\
0115268464592356253612924703951270444012674
\end{tabular} & $\mathrm{CHN}-\mathrm{QH}$ & DUR & LAN & YOR & Total \\
\hline $\mathrm{H} 1$ & CGAAT-CCGAAAA-TTTGTTCTATAATCGTATCCAGCCTGATAGTCCTC & & & & 6 & 6 \\
\hline $\mathrm{H} 2$ & ......T.TG.CACC.A....G...T............C..C.T.. & & & 3 & 15 & 18 \\
\hline H3 & T......T.TTG.CACC.A.....................C..C.T.. & & 4 & & & 4 \\
\hline $\mathrm{H} 4$ & 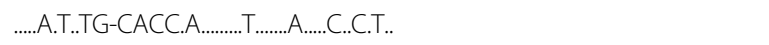 & & & & 1 & 1 \\
\hline H5 & .....-T..TG.CACCCA.T...T..A..C..C..C.T.. & & & 1 & & 1 \\
\hline H6 & ......T..TG.CACC.AC...........CT.GA..C..C..C.TC. & & 44 & 23 & 21 & 88 \\
\hline H7 & .....-TTA..G.CACC.A............T..A..C..CT.C.T.. & & & 2 & 1 & 3 \\
\hline $\mathrm{H} 8$ & ......T...G.CACC.A..T.....T......A..C..C..C.T.. & & & 2 & 2 & 4 \\
\hline H9 & 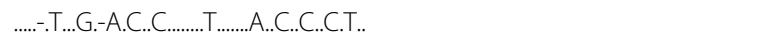 & & & 1 & & 1 \\
\hline $\mathrm{H} 10$ & $\ldots \ldots-\ldots \ldots .-$ - $\ldots . . . \ldots \ldots \ldots \ldots \ldots . . . . . . . С \ldots \ldots .$. & & & & 2 & 2 \\
\hline H11 & $\ldots \ldots .-\ldots \ldots .$. -А...СС ._................С.Т.. & & 1 & & 3 & 4 \\
\hline $\mathrm{H} 12$ & $\ldots \ldots-\ldots \ldots .-$-...С................С..С.Т.. & & 3 & 12 & 6 & 21 \\
\hline $\mathrm{H} 13$ & 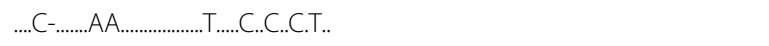 & & & 8 & 2 & 10 \\
\hline $\mathrm{H} 14$ & 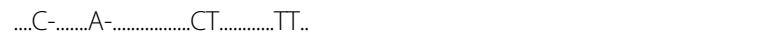 & & & 2 & & 2 \\
\hline H15 & 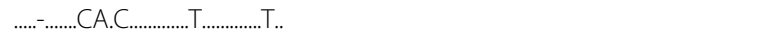 & & & & 1 & 1 \\
\hline H16 & 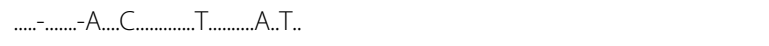 & & & 1 & 1 & 2 \\
\hline $\mathrm{H} 17$ & $\ldots \ldots-\ldots \ldots .-A \ldots . . . \ldots \ldots \ldots . . A . G \ldots \ldots \ldots \ldots . . .$. & & 27 & 1 & 13 & 41 \\
\hline $\mathrm{H} 18$ & 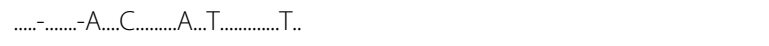 & & & & 1 & 1 \\
\hline H19 & $\ldots \ldots .-\ldots \ldots . .-A \ldots . . . \ldots \ldots \ldots \ldots \ldots \ldots \ldots \ldots . . . . .$. & & 1 & & & 1 \\
\hline $\mathrm{H} 20$ & $\ldots \ldots .-\ldots \ldots . .-A_{\ldots} \ldots . . \ldots \ldots \ldots \ldots \ldots . . . . \ldots \ldots \ldots . .$. & & & & 1 & 1 \\
\hline $\mathrm{H} 21$ & $\ldots \ldots-\ldots \ldots-A_{\ldots} \ldots . C \ldots \ldots \ldots \ldots \ldots \ldots \ldots \ldots \ldots$ & & & 2 & 2 & 4 \\
\hline $\mathrm{H} 22$ & 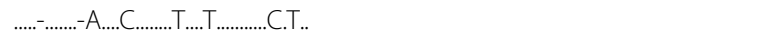 & & & & 1 & 1 \\
\hline $\mathrm{H} 23$ & $\ldots \ldots .-\ldots \ldots .$. CA.C..........T ............. & & 7 & & 3 & 10 \\
\hline $\mathrm{H} 24$ & 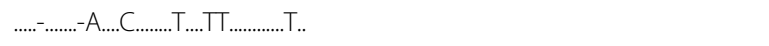 & & & & 2 & 2 \\
\hline $\mathrm{H} 25$ & $\ldots \ldots-\ldots \ldots$-A.........G.T...T..A.......... & & 1 & 8 & & 9 \\
\hline $\mathrm{H} 26$ & 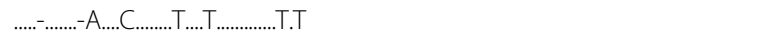 & & & 1 & & 1 \\
\hline $\mathrm{H} 27$ & 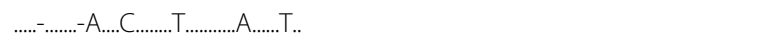 & & 1 & & & 1 \\
\hline $\mathrm{H} 28$ & $\ldots \ldots-\ldots \ldots$-A...........T.G.T...........T.. & 1 & & & & 1 \\
\hline H29 & .AG...T..TG.CACC.A.......T...............C.T.. & 1 & & & & 1 \\
\hline $\mathrm{H} 30$ & $\ldots . .$. .T.TG.CACC.A........T......AT.C..С.С.Т.. & & 1 & & & 1 \\
\hline H31 & $\ldots . .$. .T.TG.CACC.A.......T...........С..С.T.. & 10 & 6 & 29 & 51 & 96 \\
\hline H32 & $\ldots \ldots$..T..TG.CACC.AC......T................T.. & & 1 & & & 1 \\
\hline H33 & ......T..TG.CACC.A....................С..С.T.. & 6 & & & & 6 \\
\hline $\mathrm{H} 34$ & $\ldots \ldots .$. .T...G.CACC.A....CG.T................T.. & 81 & & 4 & 12 & 97 \\
\hline H35 & ...G.-T.TG.CACC.A.......T............C..C.T.. & 1 & & & & 1 \\
\hline H36 & .....-T..TG.CACC.A.......T............С..С.... & 4 & & 2 & 3 & 9 \\
\hline H37 & $\ldots \ldots$-T..TG.CACC.A.......CT.........С..С..С.T.. & 8 & & & & 8 \\
\hline H38 & .....A.T..TG.CACC.A.......T.............C..C.T.. & 1 & & & & 1 \\
\hline H39 & 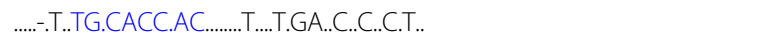 & 1 & & & & 1 \\
\hline
\end{tabular}


Table 5 The distribution of variable sites of mtDNA D-loop in pig populations (Continued)

\begin{tabular}{|c|c|c|c|c|c|c|}
\hline $\mathrm{H}$ & $\begin{array}{c}\text { Polymorphism sites } \\
22456771111111111111111222222222222223333333333444 \\
38322681122333445558888113344477788890001124699001 \\
0115268464592356253612924703951270444012674\end{array}$ & $\mathrm{CHN}-\mathrm{QH}$ & DUR & LAN & YOR & Total \\
\hline $\mathrm{H} 40$ & 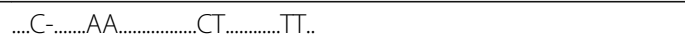 & & & & 1 & 1 \\
\hline $\mathrm{H} 41$ & 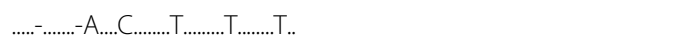 & 1 & 4 & 5 & 11 & 21 \\
\hline 42 & $\ldots \ldots-\ldots \ldots . . . A_{\ldots} \ldots . . \ldots \ldots \ldots \ldots \ldots \ldots \ldots \ldots \ldots$ & & & & 1 & 1 \\
\hline $\mathrm{H} 43$ & $\ldots \ldots-. . . . . .-$ - & & & 1 & 2 & 3 \\
\hline
\end{tabular}

H1-43: Different haplotypy

CHN-QH: Bamei pig population

DUR: Duroc pig population

LAN: Landrace pig population

YOR: Yorkshire pig population

it is even becoming a critically endangered breed. Principal component analysis (PCA) is a statistical procedure to reduce the dimensionality of a data set by transformation to a new set of variables (the principal components) to summarize the features of the data [16]. The diversity parameters, including $\mathrm{Hd}, \mathrm{Pi}$ and $\mathrm{K}$, were analyzed using PCA. Fz ranged from -2.345 to 0.405 , and its rank indicated that Bamei pigs had the lowest level of diversity, while Landrace had the highest diversity. This is consistent with the analysis of other studies which showed that indigenous pigs have a lower level of genetic diversity [17-19]. Genetic diversity is essential for continued breeding. This is especially true in the situation where future breeding goals differ from current goals [20]. The Bamei pig as an indigenous porcine breed could be a useful resource for porcine production, so the protection of the Bamei pig from extinction will be important.

\section{Introgression of commercial breeds into Qinghai indigenous breeds}

Chinese indigenous breeds are known for their low growth rate and poor feed conversion efficiency, while commercial breeds are characterized by high meat yield, fast growth rate and excellent feed efficiency, so commercial breeds have been extensively applied in the swine industry [21]. Increasing use of commercial lines threatens indigenous breeds and decreases genetic diversity. The Bamei pig similarly faces the threat of extinction due to the introgression of commercial pigs. Shared haplotypes were identified in $83.48 \%$ of Bamei pigs. Ninety-six haplotypes that were shared with commercial pigs were identified in 115 Bamei pigs. The reason for a high shared haplotype frequency in the Bamei population was crossbreeding with commercial lines. Current commercial lines were introduced and crossed with indigenous breeds, increasing the lineage of commercial lines. Despite its potentially economically unfavorable characteristics, the Bamei pig was recognized as an important genetic resource of the indigenous pig population due to specific traits (indigenous adaptation, strong adversity resistance, good maternal qualities). Additionally, the Bamei pig population was becoming small. The breeders are trying to maintain the Bamei pig breed and increase its number, so

Table 6 Analysis of native pig haplotypes shared with commercial pigs

\begin{tabular}{lllll}
\hline Code & Breed & Sc & S & Sc/S \\
\hline $\mathrm{CHN}-\mathrm{QH}$ & Bamei & 96 & 115 & $83.48 \%$ \\
\hline
\end{tabular}


the founder effect might occur, which could result in a reduction in genetic diversity.

\section{Conclusions}

Our results showed that diversity parameters, such as haplotype diversity, nucleotide diversity and the average number of nucleotide differences, of Bamei pigs were lower than those of commercial pigs. Synthetic evaluation of genetic diversity through principal component analysis indicated that Bamei pigs also have low genetic diversity. The introgression of commercial pigs into Bamei pigs was serious due to the influence of commercial pigs.

\section{Acknowledgments}

We thank Junshan Xing for help with experiments. We are grateful to Wenzhi Li and Caibao for assistance with sample collections. We thank Victoria and one of the native English speaking editors for helping in proofreading and editing the English of the final manuscript.

\section{Author contributions}

JXZ and BCY conceived and designed the experiments. JXZ and GQS performed the experiments. JXZ and WXC analyzed the data. JXZ and WXC contributed reagents/materials/analysis tools. JXZ SGQ wrote the paper. All authors read and approved the final manuscript.

\section{Funding}

This work was supported by the Young Foundation of Qinghai University (No. 2014-QNY-5).

\section{Ethics approval and consent to participate}

Studies involving animals: The animal experiments were approved by the Animal Care and Use Committee of Qinghai University, Xining, China.

\section{Consent for publication}

Not applicable.

\section{Competing interests}

The authors declare that they have no competing interest.

\section{Publisher's Note}

Springer Nature remains neutral with regard to jurisdictional claims in published maps and institutional affiliations.

Received: 6 November 2017 Accepted: 20 June 2018

Published online: 03 July 2018

\section{References}

1. Gao J, Ren J, Ken S, et al. The population genetic relationships among 47 Chinese and western pig populations inferred by AFLP markers. Chin J Anim Vet Sci. 2009;40(3):285-90.

2. The editorial committee of Chinese livestock and poultry resources. Chinese livestock and poultry resources. Beijing: Chinese Agriculture Press; 2004. p. 16.

3. Jin YC. Protection and utilization of Qinghai Bamei pig resource. Pig Prod Sci. 2006;11:70-4.

4. Kim Kl, Lee JH, Li K, et al. Phylogenetic relationships of Asian and European pig breeds determined by mitochondrial DNA D-loop sequence polymorphism. Anim Genet. 2002;33:19-25.

5. Giuffra E, Kijas JM, Amarger V, Carlborg O, Jeon JT, et al. The origin of the domestic pig: independent domestication and subsequent introgression. Genetics. 2000;154:1785-91.

6. Okumura N, Kurosawa Y, Kobayashi E. Genetic relationship amongst the major non-coding regions of mitochondrial DNAs in wild boars and several breeds of domesticated pigs. Anim Genet. 2001;32:139-47.

7. Larson G, Dobney $\mathrm{K}$, Albarella $\mathrm{U}$, et al. Worldwide phylogeography of wild boar reveals multiple centers of pig domestication. Science. 2005;307(5715):1618-21.

8. Ciesielski GL, Oliveira MT. Kaguni1 LS. Animal mitochondrial DNA replication. Enzymes. 2016;39:255-92.

9. Toro MA, Rodrigáñez JJ, Silió L. Rodr'iguez MC. Genealogical analysis of a closed herd of black hairless Iberian pigs, cons. Biol. 2000;14:1843-51.

10. Sambrook J, Frietsch EF, Maniatis T. Molecular cloning: a laboratory manual. 3rd ed. Cold Spring Harbor, NY, USA: Cold Spring Harbor Laboratory; 2001.

11. Thompson JD, Gibson TJ, Plewniak F, et al. The CLUSTAL_X windows interface: flexible strategies for multiple sequence alignment aided by quality analysis tools. Nucleic Acids Res. 1997;25:4876-82.

12. Librado P, Rozas J. DnaSP v5: a software for comprehensive analysis of DNA polymorphism data. Bioinformatics. 2009;25(11):1451-2.

13. Kim Kl, Yang YH, Lee SS. Phylogenetic relationships of Cheju horses to other breeds as determined by mtDNA Dloop sequence polymorphism. Anim Genet. 1989;30:102-8. 
14. Nei M, Tajima F. DNA polymorphism detectable by restriction endonucleases. Genetics. 1981;97:145.

15. FAO. In: Rischkowsky B, Pilling D, editors. The state of the world's animal genetic resources for food and agriculture. Rome: FAO; 2007. Available at: http://www.fao.org/docrep/010/a1250e/a1250e00.htm.

16. Jolliffe IT. Principal Component Analysis. New York: Springer; 1986.

17. Kim TH, Kim KS, Choi BH. Genetic structure of pig breeds from Korea and China using microsatellite loci analysis. J Anim Sci. 2005;83:2255-63.

18. Kim KS, Yeo JS, Kim JW. Assessment of genetic diversity of Korean native pig (Sus scrofa) using AFLP markers. Gen Genet Syst. 2002b;77:361-8.

19. Li KY, Chen C, Moran BF, Zhao S, Peng Z. Analysis of diversity and genetic relationships between four Chinese indigenous pig breeds and one Australian commercial pig breed. Anim Genet. 2000;31:322-5.

20. China national commission of animal genetic resources. Animal genetic resources in China pigs. Beijing: Chinese Agriculture Press; 2011.

21. Ai HS, Huang LS, Ren J. Genetic diversity, linkage disequilibrium and selection signatures in Chinese and western pigs revealed by genome-wide SNP markers. PLoS One. 2013;8(2):e56001.

Ready to submit your research? Choose BMC and benefit from:

- fast, convenient online submission

- thorough peer review by experienced researchers in your field

- rapid publication on acceptance

- support for research data, including large and complex data types

- gold Open Access which fosters wider collaboration and increased citations

- maximum visibility for your research: over $100 \mathrm{M}$ website views per year 